\title{
A simple synthesis of well-ordered super-microporous aluminosilicate
}

\author{
Yu-Shen Lin ${ }^{\mathrm{a}}$, Hong-Ping Lin ${ }^{\mathrm{b}}$, Chung-Yuan Mou ${ }^{\mathrm{a}, \mathrm{c}, *}$ \\ a Department of Chemistry, National Taiwan University, Taipei 106, Taiwan \\ ${ }^{\mathrm{b}}$ Department of Chemistry, National Cheng Kung University, Tainan 701, Taiwan \\ ${ }^{c}$ Center for Condensed Matter Sciences, National Taiwan University, Taipei 106, Taiwan
}

Received 10 May 2004; received in revised form 13 August 2004; accepted 17 August 2004

\begin{abstract}
We report a simple preparation of highly ordered super-microporous silica with a surfactant/co-surfactant system containing short-chain cationic surfactant (decyltrimethyl ammonium bromide) and butanol as the templating agents. The XRD data and $\mathrm{N}_{2}$ adsorption-desorption isotherm showing the calcined silica exhibits narrow hexagonal (100) peak with $d$-spacing as low as $2.28 \mathrm{~nm}$ and an adsorption isotherm behavior between those of microporous and mesoporous materials. To confirm the pore size falls in the super-microporous range, we use various methods including nitrogen adsorption and TEM observation to estimate the primary pore diameters at $1.5 \mathrm{~nm}$. The results show that we have successfully synthesized porous silica with very uniform pores in the super-microporous regime. The super-microporous materials can also incorporate aluminum up to $\mathrm{Si} / \mathrm{Al}=30$ without structural deterioration.
\end{abstract}

(C) 2004 Elsevier Inc. All rights reserved.

Keywords: Super-microporous silica; Pore size; Cationic surfactant; Co-surfactant; Butanol

\section{Introduction}

Since the first discovery of mesoporous molecular sieve (M41S) at Mobil Oil Corporation in 1992 [1], considerable efforts have been concentrated on the synthesis of tailored pore structure and size, which may have extensive applications in shape-selective catalysis [2], molecular separation [3], and drug delivery [4]. Because microporous crystalline zeolites have been shown to be useful for separation, catalytic, and other applications, the synthesis of super-microporous silica with pore sizes between those of the upper limit of zeolites $(1.2 \mathrm{~nm})$ and the lower end of mesoporous materials would be attractive. Up to the present, only a few works have been focused on the synthesis of ordered super-microporous silica (pore size falls between 1-2 nm) [5-12]. However,

\footnotetext{
${ }^{*}$ Corresponding author. Tel.: +886 233665251; fax: +886 233660954.

E-mail address: cymou@ntu.edu.tw (C.-Y. Mou).
}

the super-microporous silica materials reported so far possess either relatively large pore [8] $(\sim 2.0 \mathrm{~nm}$ or above) or rather disordered worm-like structure (hence a broad size distribution) [7,11].

In several research directions, there is a critical need for ordered super-microporous silicas with narrow size distribution. In the pore size range of $1.0-2.0 \mathrm{~nm}$, the determination of pore size by gas adsorption is still an open issue for lack of standard samples of well-defined pore sizes [13]. Secondly, in the investigation of the confinement effects on chemical reactions, the size near $1.5 \mathrm{~nm}$ is an important one to show critical size effect. For example, we have found the hydrocracking of 1,3,5-triisopropylbenzene in MCM-41 depends on the pore size [14]. The effect has been traced to the sizedependence of diffusion rate in the mesopores. Recently, it is found that the delivery rate of the drug ibuprofen in a simulated body fluid decreases with the pore size of MCM-41 when it is used to embed the drug [15]. Therefore the availability of mesoporous materials of pore size 
around $1.5 \mathrm{~nm}$ with narrow size distribution is important for many applications.

Up to the present, most of the reported super-microporous silicas used either specially designed surfactants such as bolaform [5], adamantanamine [7], short double chain alkylammoniums [9] or ionic liquids [12] as templates. It would be desirable to use simple short-chain alkyltrimethylammonium halides as templates as in the standard synthesis of MCM-41. In fact, this was done with dodecyltrimethylammonium bromide $\left(\mathrm{C}_{12} \mathrm{TMAB}\right)$ and cetyltrimethylammonium bromide $\left(\mathrm{C}_{14} \mathrm{TMAB}\right)$ surfactants as templates [6]. However, the resulting pore mesostructure was worm-like and the pore size distribution was broad. This is because the alkyl chains are too short to properly maintain good micellar structures. Previously, we reported that the addition of short-chain alcohol co-surfactants in the synthesis of MCM-41 could dramatically improve its structure order [16].

In this work, we report a simple synthesis of mesoporus silica based on our previously reported delayed immediate acidification method [17] to give highly ordered super-microporous aluminosilicate using a common short-chain quaternary ammonium surfactant (decyltrimethylammonium bromide, $\mathrm{C}_{10} \mathrm{TMAB}$ ) mixing together with the co-surfactant butanol as templating agent.

\section{Experimental section}

\subsection{Materials}

All silica samples were synthesized using sodium silicate $\left(27 \% \mathrm{SiO}_{2}, 14 \% \mathrm{NaOH}\right)$ as silica source obtained from Aldrich. The short-chain quaternary ammonium surfactant, decyltrimethyl ammonium bromide $\left(\mathrm{C}_{10} \mathrm{TMAB}, 99 \%\right)$, and alcohols were obtained from Acrôs. Sulfuric acid as acid source was obtained from Acrôs. The aluminum source, sodium aluminate was purchased from Riedel-de-Haën. All chemicals were used without further purification.

\subsection{Synthesis procedure}

The ordered super-microporous silicas were prepared by the following steps. $1.2 \mathrm{~g} \mathrm{C}_{10} \mathrm{TMAB}$ surfactant was dissolved in $8 \mathrm{~g}$ distilled water. A proper amount of alcohol (butanol for example) was added to the $\mathrm{C}_{10} \mathrm{TMAB}$ aqueous solution. Then $4.5 \mathrm{~g}$ sodium silicate was added and the solution was stirred vigorously for about $10 \mathrm{~min}$ at $25^{\circ} \mathrm{C}$. Finally, $5.0 \mathrm{~mL}$ of $1.2 \mathrm{M} \mathrm{H}_{2} \mathrm{SO}_{4}$ was quickly added to the gel mixture, and the $\mathrm{pH}$ value dropped to about 9. The molar composition ratio of the resultant mixture gel was $1.00 \mathrm{C}_{10} \mathrm{TMAB}: 4.70 \mathrm{SiO}_{2}$ : $3.70 \mathrm{NaOH}: 1.40 \mathrm{H}_{2} \mathrm{SO}_{4}: 0.94 \mathrm{BuOH}: 100 \mathrm{H}_{2} \mathrm{O}$. After complete acidification and silica condensation, the gel was filtered, washed and dried in air at $100^{\circ} \mathrm{C}$ overnight. The as-synthesized product was calcined at $560^{\circ} \mathrm{C}$ in air for 6 hours to remove organic template. The resulting powder is designated as $\mathrm{C}_{10}$-MCM41. The aluminum containing $\mathrm{C}_{10}$-MCM41 were synthesized similar to the abovementioned procedure except a proper amount of sodium aluminate was added to the surfactant solution.

\subsection{Characterization}

The powder X-ray patterns were acquired on a Scintag X1 diffractometer $(40 \mathrm{kV}, 30 \mathrm{~mA})$ with $\mathrm{CuK}_{\alpha}$ radiation $(\lambda=0.154 \mathrm{~nm}) . \mathrm{N}_{2}$ adsorption-desorption isotherms were obtained at $77 \mathrm{~K}$ on a Micrometrics ASAP 2010 analyzer. Before sorption measurements, the calcined samples were degassed at $200^{\circ} \mathrm{C}$ for more than $6 \mathrm{~h}$ under $10^{-3}$ Torr pressure. The nitrogen BET specific surface area was calculated from adsorption data in the $P / P_{0}$ from 0.01 to 0.02 . The pore size determination using $W_{4 \mathrm{~V} / \mathrm{s}}$ and $W_{\mathrm{d}}$ methods were calculated according to Refs. $[18,19]$. The TEM images were recorded on the JEOL-JSM-1200EX II operating at an acceleration voltage of $80 \mathrm{kV}$. Thermogravimetric analysis was performed on NETZSCH TG209 thermogravimetric analyzer. In a typical experiment, about $10 \mathrm{mg}$ of sample was examined at a heating rate of $10^{\circ} \mathrm{C} / \mathrm{min}$ under dried air.

\section{Results and discussion}

Let us examine the structure order of the mesoporous silica prepared using $\mathrm{C}_{10} \mathrm{TMAB}$ with or without the cosurfactant butanol. Fig. 1 shows the XRD patterns of the products. Fig. 1(a) shows that the hexagonal mesostructural order of the calcined product of $\mathrm{C}_{10} \mathrm{TMAB}$

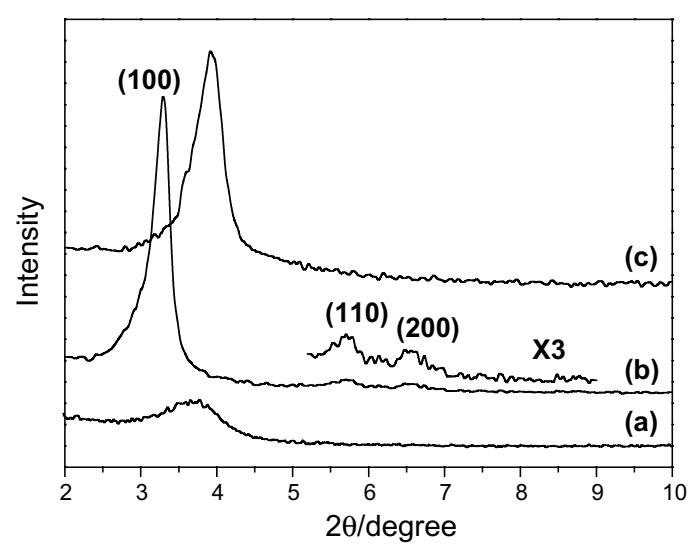

Fig. 1. XRD patterns of super-microporous silica (a) calcined sample using only $\mathrm{C}_{10} \mathrm{TMAB}$ surfactant as template $\left(\mathrm{C}_{10} \mathrm{MS}\right)$ (b) as-synthesized sample using $\mathrm{C}_{10} \mathrm{TMAB}$ and the butanol co-surfactant as templates $\left(\mathrm{C}_{10} \mathrm{MS}-\mathrm{B}\right)$, and (c) $\mathrm{C}_{10} \mathrm{MS}-\mathrm{B}$ after calcinations at $560^{\circ} \mathrm{C} 6 \mathrm{~h}$. 
templated mesoporous silica is rather poor (denoted as $\mathrm{C}_{10} \mathrm{MS}$ ). One can barely see the broad (100) peak. After incorporation of butanol (denoted as $\mathrm{C}_{10} \mathrm{MS}-\mathrm{B}$ ), its structure order is much improved (Fig. 1(b)) with a (100) inter-planar spacing of $2.68 \mathrm{~nm}$. The structure order of $\mathrm{C}_{10} \mathrm{MS}-\mathrm{B}$ is so good that one can observe the (110) and (200) peaks. The $d_{(100)}$ spacing can be further reduced after calcinations where one obtains a well-ordered structure with $(100)$ spacing reduced to $2.28 \mathrm{~nm}$ (Fig. 1(c)). The good mesostructure order in the calcined $\mathrm{C}_{10}$ MS-B sample is further confirmed by its nitrogen adsorption data. Its BET surface area still maintains a high value of $980 \mathrm{~m}^{2} / \mathrm{g}$. In all the super-microporous silica of comparable basal (100) spacings reported in literature, the BET surface areas are below $800 \mathrm{~m}^{2} / \mathrm{g}[6,7,11]$. Previously, we have shown the effect of alcohol addition in synthesizing mesoporous silica [16,17]. Alcohols were classified either as a co-surfactant that mainly help building up the mesostructure or as co-solvent which tends to break up the micellar structure and make worse structure order. Alcohol of proper chain length, when staying in the palisade-layer as co-surfactant, would lower the inter-facial curvature and elongate the cationic surfactant micelles. Butanol was classified as co-surfactant $[16,17]$. From the XRD patterns in Fig. 1, this is indeed true that structure order of $\mathrm{C}_{10} \mathrm{MS}-\mathrm{B}$ is much improved.

For finding the most suitable alcohol for the improvement on the mesostructure, we varied the chain length of the alcohol, from $\mathrm{C}_{2}$ to $\mathrm{C}_{5}$, at the fixed molar ratio alco$\mathrm{hol} / \mathrm{C}_{10} \mathrm{TMAB}=0.94$ in synthesizing the $\mathrm{C}_{10} \mathrm{TMAB}-$ templated silicas. The structure order is compared in Fig. 2. For ethanol- and propanol-added sample it is clearly shown that the mesoporous silica has worse structural order with only a broad (100) peak. When butanol or pentanol was added, well-ordered mesopor-

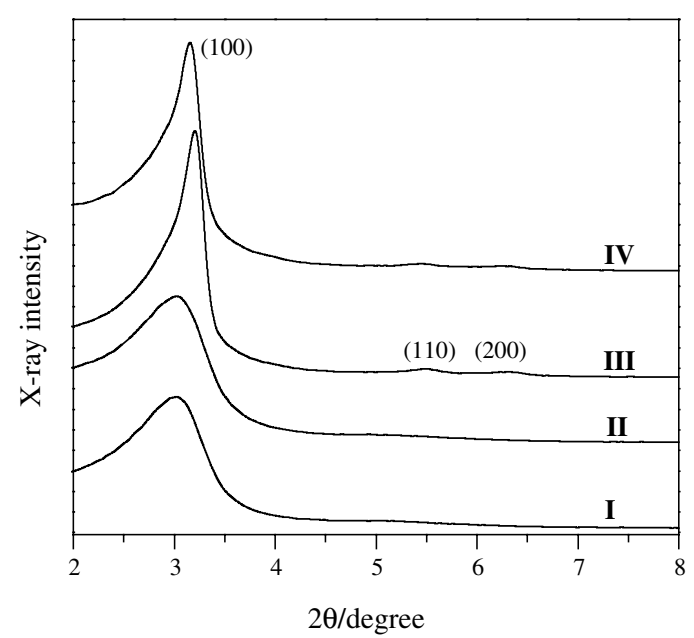

Fig. 2. The XRD patterns of the as-synthesized mesoporous silicas with different alcohols at the alcohol $/ \mathrm{C}_{10} \mathrm{TMAB}$ molar ratio $=0.94$. (I) Ethanol, (II) propanol, (III) butanol, and (IV) pentanol. ous silica with three XRD peaks ((100), (110) and (200)) for the 2-D hexagonal arrangement, was obtained. From the XRD data, it may be concluded alcohols of chain length shorter than four do not have enough hydrophobicity to serve as structural promoting co-surfactant for elongating micelles. One also finds that the mesoporous silica with pentanol addition has a larger d-spacing than that with butanol. The increase in the unit cell may be ascribed to the penetration of pentanol molecules deeper into the hydrophobic core of the $\mathrm{C}_{10} \mathrm{TMAB}$ micelles which swells the pore size. Thus, butanol with the proper chain length has the best capability to improve the mesostructural orderness of the $\mathrm{C}_{10} \mathrm{TMAB}$-templated silica without expanding the pore size. In the rest of this paper, we will thus focus only on using butanol as co-surfactant.

We also vary the relative amount of butanol used in synthesis. The resulting structure order for as-synthesized materials can be examined in the XRD pattern in Fig. 3. One can see there is an optimum ratio for structure order at butanol $/ \mathrm{C}_{10} \mathrm{TMAB}=0.94$. For butanol concentration higher than this ratio, the micellar structure cannot be maintained as well. We also vary the kind of alcohol to see the effect of carbon chain length. Previously, Yano and Fukushima [20] have synthesized hexagonally ordered super-microporous silicas using $\mathrm{C}_{10}$ TMAB. Their use of TMOS as silica source probably helps building a good structural order.

Hereafter, we examine in further detail the case of butanol $/ \mathrm{C}_{10} \mathrm{TMAB}=0.94$. For textural properties, Fig. 4(b) shows a detectable capillary rise of adsorption down to a $P / P_{0}$ value below 0.1 . In contrast, the calcined

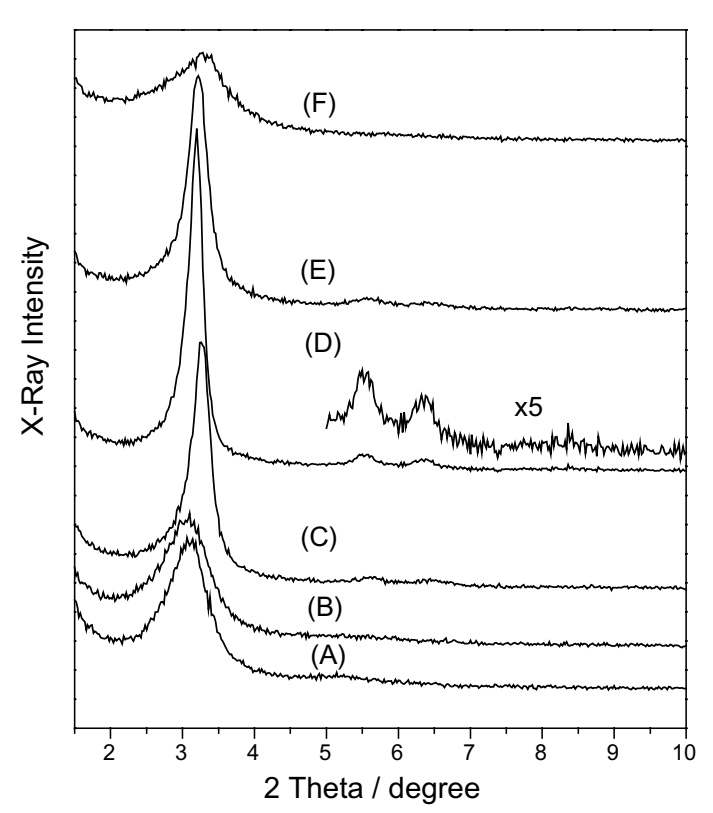

Fig. 3. XRD patterns of as-synthesized microporous silica at various ratio of $\mathrm{BuOH} / \mathrm{C}_{10}$ TMAB: (A) 0, (B) 0.32, (C) 0.63, (D) 0.94, (E) 1.26, and (F) 1.89 . 


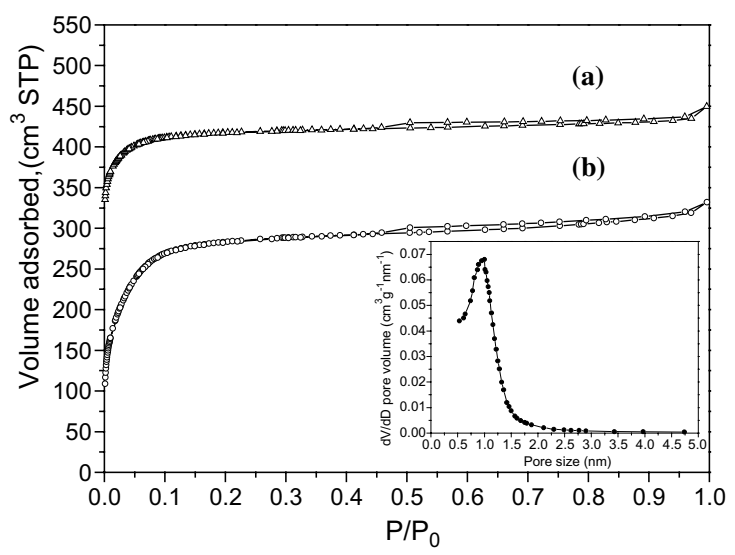

Fig. 4. Nitrogen adsorption-desorption isotherms of (a) calcined $\mathrm{C}_{10} \mathrm{MS}$ (b) calcined $\mathrm{C}_{10} \mathrm{MS}-\mathrm{B}$. The inset figure is the $\mathrm{BJH}$ pore size distribution of calcined $\mathrm{C}_{10}$ MS-B (a) has been shifted upwards by $250 \mathrm{~cm}^{3}$ for clarity.

$\mathrm{C}_{10} \mathrm{MS}$ (without butanol) of Fig. 4(a) shows a much lower BET surface area $\left(630 \mathrm{~m}^{2} / \mathrm{g}\right)$ due to structural deterioration. The pore seems mostly microporous; one cannot detect a BJH pore size distribution maximum at all.

Fig. 5 gives the TEM images of the $\mathrm{C}_{10}$ MS-B samples. Fig. $5(\mathrm{a})$ is for the as-synthesized $\mathrm{C}_{10} \mathrm{MS}-\mathrm{B}$ sample. The structure order of the hexagonal channel is very good. After calcination, its structure is still maintained (Fig. 5(b)). The average distances between channels measured from TEM image agree with that determined from XRD (Table 1). In most of the hexagonal supermicroporous silica reported in the literatures, the TEM images, if ever present, always show disordered or worm-like structures [5-8]. Without the use of butanol, our $\mathrm{C}_{10} \mathrm{MS}$ samples also give highly disordered structure (TEM not shown here).

The precise determination of the pore sizes for supermicroporous materials is still a matter of uncertainty. Different calculation methods have been used in different papers, and one cannot directly compare those reported pore sizes. In fact, one of our motivations of this work is to provide well-ordered standard sample
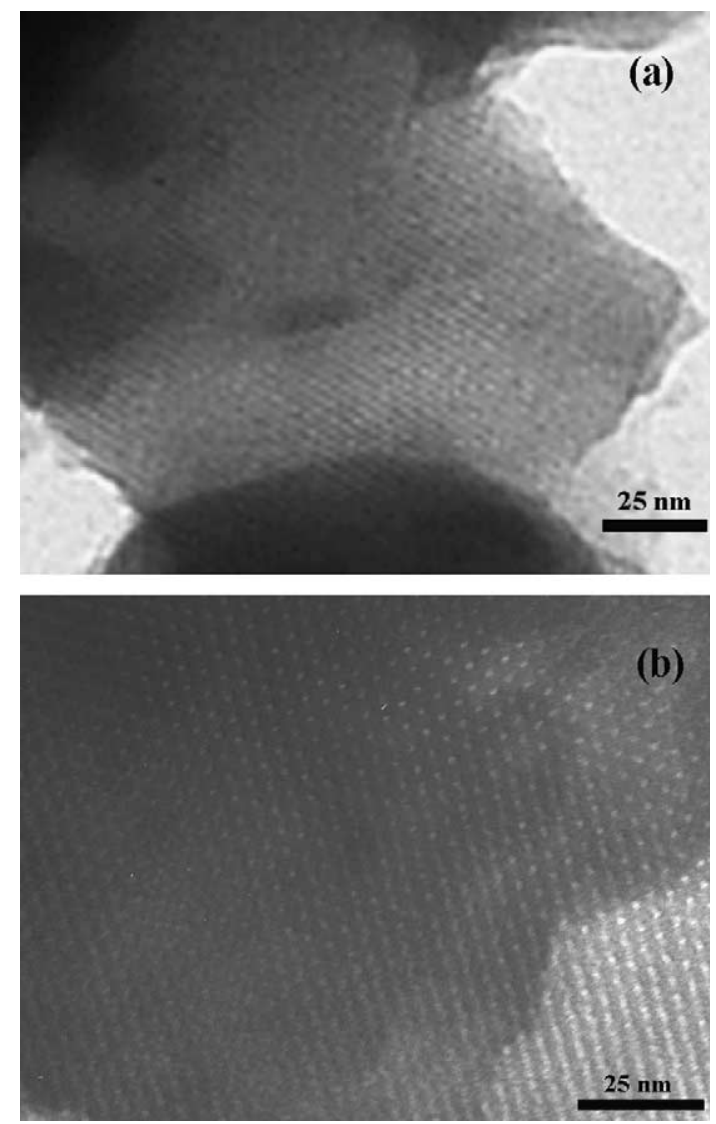

Fig. 5. TEM images of (a) as-synthesized $\mathrm{C}_{10} \mathrm{MS}-\mathrm{B}$ and (b) calcined $\mathrm{C}_{10} \mathrm{MS}-\mathrm{B}$.

in the super-microporous range so that methods on pore size determination can be further developed. In this paper, we report the pore sizes determined by three methods: the standard $\mathrm{BJH}$ method, $W_{4 \mathrm{~V} / \mathrm{s}}$ method [18] and the geometric determination $W_{\mathrm{d}}$ [19]. The latter two methods, based on geometrical considerations, assume well-defined pore structures. They are thus not applicable to the $\mathrm{C}_{10} \mathrm{MS}$ sample which is disordered. For $W_{4 \mathrm{~V} / \mathrm{S}}$, pore diameters are calculated from the primary pore volume $\left(V_{\mathrm{p}}\right)$ and primary surface area $\left(S_{\mathrm{p}}\right.$, the difference between $S_{\mathrm{BET}}$ and $S_{\mathrm{ex}}$ ) by assuming uniform cylindrical pore shape. (Eq. (1)) [18]

Table 1

Structural and textural data of calcined $\mathrm{C}_{10} \mathrm{MS}$ porous silicas ${ }^{\mathrm{a}}$

\begin{tabular}{|c|c|c|c|c|c|c|c|c|c|c|}
\hline Sample & $\begin{array}{l}d_{100} \\
(\mathrm{~nm})\end{array}$ & $\begin{array}{l}a \\
(\mathrm{~nm})\end{array}$ & $\begin{array}{l}S_{\mathrm{BET}} \\
\left(\mathrm{m}^{2} \mathrm{~g}^{-1}\right)\end{array}$ & $\begin{array}{l}V_{t} \\
\left(\mathrm{~cm}^{3} \mathrm{~g}^{-1}\right)\end{array}$ & $\begin{array}{l}V_{\mathrm{p}} \\
\left(\mathrm{cm}^{3} \mathrm{~g}^{-1}\right)\end{array}$ & $\begin{array}{l}S_{\mathrm{ex}} \\
\left(\mathrm{m}^{2} \mathrm{~g}^{-1}\right)\end{array}$ & $\begin{array}{l}S_{\mathrm{P}} \\
\left(\mathrm{m}^{2} \mathrm{~g}^{-1}\right)\end{array}$ & $\begin{array}{l}W_{\text {BJH }} \\
(\mathrm{nm})\end{array}$ & $\begin{array}{l}W_{4 \mathrm{~V} / \mathrm{S}} \\
(\mathrm{nm})\end{array}$ & $\begin{array}{l}W_{\mathrm{d}} \\
(\mathrm{nm})\end{array}$ \\
\hline $\mathrm{C}_{10} \mathrm{MS}-\mathrm{B}$ & 2.28 & 2.63 & 980 & 0.52 & 0.46 & 20 & 960 & 1.00 & 1.92 & 1.96 \\
\hline $\mathrm{C}_{10} \mathrm{MS}$ & 2.34 & 2.70 & 630 & 0.30 & 0.27 & 20 & 610 & - & - & - \\
\hline $\mathrm{Al}-\mathrm{C}_{10} \mathrm{MS}-\mathrm{B} 90$ & 2.33 & 2.69 & 980 & 0.53 & 0.47 & 20 & 960 & 0.98 & 1.96 & 2.01 \\
\hline $\mathrm{Al}-\mathrm{C}_{10} \mathrm{MS}-\mathrm{B} 60$ & 2.34 & 2.70 & 930 & 0.50 & 0.45 & 20 & 910 & 0.94 & 1.97 & 2.00 \\
\hline $\mathrm{Al}-\mathrm{C}_{10} \mathrm{MS}-\mathrm{B} 30$ & 2.36 & 2.72 & 890 & 0.49 & 0.43 & 30 & 860 & 1.05 & 2.00 & 2.00 \\
\hline
\end{tabular}

${ }^{a}$ Notation: $d_{100},(100)$ inter-planar spacing; $a$, unit cell length of hexagonal packing structure; $S_{\mathrm{BET}}$, BET specific surface area; $V_{\mathrm{t}}$, total pore volume; $V_{\mathrm{p}}$, primary pore volume; $S_{\mathrm{ex}}$, external surface area obtained from $t$-plot according to Ref. [18]; $S_{\mathrm{P}}$, primary surface area; $W_{\mathrm{BJH}}$, pore diameter assigned from the maximum on the BJH pore size distribution; $W_{4 \mathrm{~V} / \mathrm{s}}$, pore diameter from Eq. (1); $W_{\mathrm{d}}$, pore diameter calculated from Eq. (2). 
Table 2

Comparison of the $d$-spacings of super-microporous silica in literature

\begin{tabular}{llll}
\hline References & Materials & $d$-spacing $(\mathrm{nm})$ & Pore structure \\
\hline$[8]$ & HMS, MSU & $3.1-5.5$ & Worm-like \\
{$[18]$} & [C8] & 2.83 & Worm-like \\
{$[11]$} & Vinyl functionalized silica & $2.63-3.30$ & Worm-like to 2-D hex \\
{$[5]$} & 3-D cubic & 2.97 & P6 \\
$3 /$ mmc \\
{$[12]$} & Ionic liquid templated silica $\left(I_{10}\right)$ & 2.7 & Lamellar \\
This work & C $_{10}$-MCM-41 & 2.28 & Well-ordered 2-D hex \\
\hline
\end{tabular}

$W_{4 \mathrm{~V} / \mathrm{S}}=\frac{4 V_{\mathrm{p}}}{S_{\mathrm{p}}}$

$W_{\mathrm{d}}$ is obtained from geometric consideration assuming a 2-D honeycomb structure of channels. In Eq. (2), $c$ is a constant equal to $1.213, \rho$ is assumed to be the silica density of $2.2 \mathrm{~g} / \mathrm{cm}^{3}, V_{\mathrm{p}}$ is the primary pore volume and $d_{100}$ is the inter-planar spacing.

$W_{d}=c d_{100}\left(\frac{\rho V_{\mathrm{p}}}{1+\rho V_{\mathrm{p}}}\right)^{1 / 2}$

In Table 1, we list the structural and textural data for the super-microporous aluminosilicate discussed in this work. One can see that the (100) $d$-spacing difference for $\mathrm{C}_{10} \mathrm{MS}-\mathrm{B}$ and $\mathrm{C}_{10} \mathrm{MS}$ is not much different. This indicates that butanol does not reside in the core to expand the pore. But the structural order of $\mathrm{C}_{10} \mathrm{MS}-\mathrm{B}$ is much better than $\mathrm{C}_{10} \mathrm{MS}$, giving larger surface area, pore volume and much stronger XRD peak. For the surfactant-alcohol-water ternary system, it is known that medium chain length alcohol may reside in the palisade layer of the micelles to favor micellar structure of less surface curvature [21]. For the short-chain $\mathrm{C}_{10}$ surfactant employed in this work, it tends to form the spherical micelle. When adding a proper amount of butanol, the surface curvature of the surfactant micelle decreases to form the better structured rod-like micelle with lower surface curvature. Apparently, this trend also holds in the presence of sodium silicate [17]. For the $\mathrm{C}_{10} \mathrm{MS}-\mathrm{B}$ sample, the three methods give different results of pore size. While it is known BJH method underestimates the pore size, the use of the bulk silica density in calculating $W_{\mathrm{d}}$ certainly overestimated the pore diameter. It is unlikely the pore wall has a densely packed silica microstructure as bulk silica density would indicate. In Table 1 one sees that there is in general a $10 \%$ difference between total pore volume and $V_{\mathrm{p}}$. This indicates that there are unaccounted micropores which may lower the silica density of the wall. If one were using pore size as $1.96 \mathrm{~nm}\left(W_{\mathrm{d}}\right)$ or $1.92 \mathrm{~nm}\left(W_{4 \mathrm{~V} / \mathrm{S}}\right)$ for $\mathrm{C}_{10} \mathrm{MS}-\mathrm{B}$, one would have an unlikely small wall thickness of 0.67 or $0.71 \mathrm{~nm}$. Thus the geometrical methods probably overestimate the pore size in the super-microporous range. We also note here thermogravity analysis (TGA) gives a relatively small weight loss about $35 \%$ for the organic template in $\mathrm{C}_{10} \mathrm{MS}-\mathrm{B}$ indicating rather small pores. The actual pore size of $\mathrm{C}_{10} \mathrm{MS}-\mathrm{B}$ must be between the two estimates, $W_{\mathrm{BJH}}$ and $W_{\mathrm{d}}$. Close examination of the TEM image in Fig. 4(b) could also give us an estimate of the pore size at $1.5 \mathrm{~nm}$. One also notes that the channel walls become less uniform after calcinations. Nonetheless, our sample is probably the best ordered super-microporous silica in this size range. It may serve as a standard materials for developing good method for the estimations of pore sizes in the future. In Table 2, we compare the $d$-spacings of our super-microporous silica with those reported previously in the literature. From Table 2, we can see the super-microporous silica of this work has the smallest $d$-spacing where the structure is well-ordered 2-D hexagonal. In many of the literature results, the structures are either worm-like or lamellar (see Table 2).

We also investigated aluminum incorporation into the super-microporous materials, which may be important in acid catalysis applications. We are able to incorporate $\mathrm{Al}$ up to the $\mathrm{Si} / \mathrm{Al}$ ratio of 30 without affecting much the structure. Fig. 6 gives the XRD patterns for the $\mathrm{Al}-\mathrm{C}_{10} \mathrm{MS}-\mathrm{B} x$ calcined samples (the $x$ appended at the end is the Si/Al ratio). They all give a fairly good hexagonal structure order. When the Al is increased, there is a slight deterioration of the structural order. Table 1 presents the textural data for $\mathrm{Al}-\mathrm{C}_{10} \mathrm{MS}-\mathrm{B} x$. Surface area and pore size are fairly close to that of pure

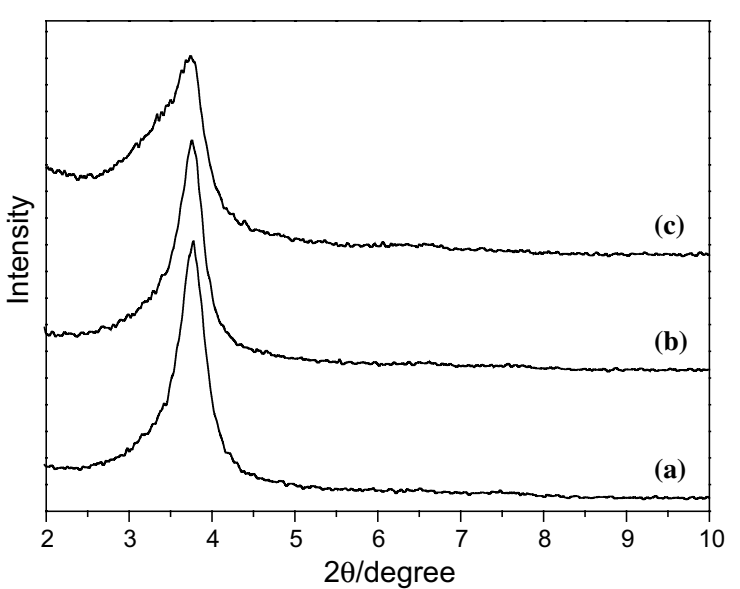

Fig. 6. XRD patterns of calcined (a) Al- $\mathrm{C}_{10} \mathrm{MS}-\mathrm{B} 90$, (b) $\mathrm{Al}-\mathrm{C}_{10} \mathrm{MS}-$ $\mathrm{B} 60$ and (c) Al-C $10 \mathrm{MS}-\mathrm{B} 30$. 
silica $\mathrm{C}_{10} \mathrm{MS}-\mathrm{B}$. The co-ordination environments of aluminum in the as-synthesized and calcined supermicroporous aluminosilicate were examined by ${ }^{29} \mathrm{Al}$ MAS NMR spectroscopy. Spectrum for as-synthesized sample (Al- $\left.\mathrm{C}_{10} \mathrm{MS}-\mathrm{B} 30\right)$ shows only a peak at $55 \mathrm{ppm}$ indicating that the aluminum in as-synthesized supermicroporous aluminosilicate is completely in the tetrahedral co-ordination. After calcinations there is only little $(<10 \%)$ octahedral aluminum. The acidic Al-containing super-microporous aluminosilicate may be useful in size selective catalysis application in the future.

In addition to the use of the co-surfactant butanol, another important factor in our obtaining well-ordered structure is the use of delayed neutralization method $[17,22]$.

We quickly add sulfuric acid to the synthetic gel so that its $\mathrm{pH}$ value was brought down to 9. It was observed that the delayed fast neutralization process would favor a better structure order and thicker wall leading to better stability after calcinations [17]. This is because of more complete silica condensation under the lower $\mathrm{pH}$ value of around 9.0.

\section{Conclusion}

Hexagonally ordered aluminosilicates with narrow pore size distribution in the super-microporous range were successfully synthesized using the readily available short-chain surfactant decyltrimethylammonium bromide and co-surfactant butanol as the templates. The co-surfactant helps in adjusting the packing behavior of the surfactant micelle to result in well-ordered cylindrical structure in the surfactant/silicate composite. The structure is so well ordered that they retain excellent parallel channel structure after calcinations. On the basis of published structural and textural data, we conclude the degree of ordering in the $\mathrm{C}_{10}$ MS-B materials reported herein surpasses those in the literature in the super-microporous range. The synthesis of $\mathrm{C}_{10} \mathrm{MS}-\mathrm{B}$ materials is simple and straightforward without the use of specially designed surfactant system as structure directing agent. Incorporation of aluminum is also easy without changing its textural properties. The $\mathrm{C}_{10} \mathrm{MS}-\mathrm{B}$ materials may be useful in catalysis, separation and in gas adsorption studies.

\section{Acknowledgment}

This work was supported by a grant from the Ministry of Education through Academy Excellent program. Helps from Dr. Y. Hung and Ms. M.C. Chao are acknowledged.

\section{References}

[1] J.S. Beck, J.C. Vartuli, W.J. Roth, M.E. Leonowicz, C.T. Kresge, K.D. Schmitt, T.W.-C. Chu, D.H. Olson, E.W. Sheppard, S.B. Higgins, J.L. Schlenker, J. Am. Chem. Soc. 114 (1992) 10834.

[2] T.F. Degnan, J. Catal. 216 (2003) 32.

[3] B.L. Newalkar, N.V. Choudary, U.T. Turaga, R.P. Vijayalakshmi, P. Kumar, S. Komarneni, T.S.G. Bhat, Chem. Mater. 15 (2003) 1474.

[4] N.K. Mal, M. Fujiwara, Y. Tanaka, Nature 421 (2003) 350.

[5] S.A. Bagshaw, A.R. Hayman, Chem. Comm. (2000) 533.

[6] D.P. Serrano, J. Aguado, J.M. Escola, E. Garagorri, Chem. Comm. (2000) 2041.

[7] T. Sun, M.S. Wong, J.Y. Ying, Chem. Comm. (2000) 2057.

[8] M.D. McInall, J. Scott, L. Mercier, P.J. Kooyman, Chem. Comm. (2001) 2282.

[9] R. Ryoo, I.-S. Park, S. Jun, C.W. Lee, M. Kruk, M. Jaroniec, J. Am. Chem. Soc. 123 (2001) 1650.

[10] E.B. Gonzalez, R. Mokaya, W. Jones, Chem. Comm. (2001) 1061.

[11] M. Kruk, T. Asefa, M. Jaroniec, G.A. Ozin, J. Am. Chem. Soc. 123 (2002) 6383.

[12] (a) Y. Zhou, M. Antonietti, Adv. Mater. 15 (2003) 1452; (b) Y. Zhou, M. Antonietti, Chem. Mater. 16 (2004) 544.

[13] M. Jaroniec, M. Kruk, Stud. Surf. Sci. Catal. 146 (2003) 263.

[14] W.-H. Chen, Q. Zhao, S.-J. Huang, C.-Y. Mou, S.-B. Liu, Stud. Surf. Sci. Catal. 146 (2003) 681.

[15] P. Horcajada, A. Rámila, J.P. Pariente, M. Vallet-Regí, Micropor. Mesopor. Mater. 68 (2004) 105.

[16] H.-P. Lin, S. Cheng, C.-Y. Mou, J. Mater. Chem. 9 (1999) 1197.

[17] H.-P. Lin, S. Cheng, C.-Y. Mou, Micropor. Mater. 10 (1997) 111.

[18] M. Kruk, M. Jaroniec, J. Phys. Chem. B 101 (1997) 583.

[19] M. Kruk, M. Jaroniec, A. Sayari, Chem. Mater. 11 (1999) 492.

[20] K. Yano, Y. Fukushima, Bull. Chem. Soc. Jpn. 76 (2003) 2103.

[21] M.E. Morgan, H. Uchiyama, S.D. Christian, E.E. Tucker, J.F. Scamerhorn, Langmuir 10 (1994) 2170.

[22] H.-P. Lin, S. Cheng, C.-Y. Mou, J. Chin. Chem. Soc. 43 (1996) 375. 